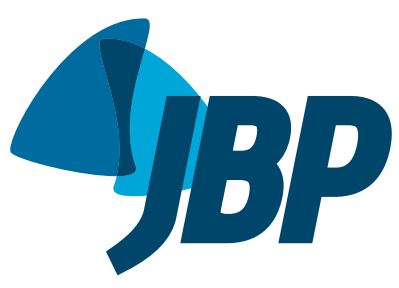

. Programa de Pós-Graduação em Ciência ropical, Universidade Federa Rural de Pernambuco - UFRPE Recife (PE) Brasil.

2. Departamento de Morfologia e Fisiologia Animal, Universidade Federal Rural de Pernambuco - UFRPE Recife (PE) Brasil.

3. Hospital Geral Otávio de Freitas - HGOF - Recife (PE) Brasil.

a. (iD http://orcid.org/0000-0001-8686-0834

b. iD http://orcid.org/0000-0003-1493-7964

c. (iD http://orcid.org/0000-0003-1935-1540

d. (iD) http://orcid.org/0000-0003-0794-1228

e. iD http://orcid.org/0000-0002-4224-4009

Submitted: 7 February 2017

Accepted: 7 December 2017

Study carried out in the Ambulatório de Pneumologia, Hospital Otávio de Freitas HGOF - Recife (PE) Brasil.

\section{Correlation of lung function and respiratory muscle strength with functional exercise capacity in obese individuals with obstructive sleep apnea syndrome}

\author{
Thays Maria da Conceição Silva Carvalho ${ }^{1, a}$, Anísio Francisco Soares ${ }^{2, b}$ \\ Danielle Cristina Silva Climaco ${ }^{3, c}$, Isaac Vieira Secundo,d, \\ Anna Myrna Jaguaribe de Lima2,e
}

\begin{abstract}
Objective: To evaluate lung function and inspiratory muscle strength, correlating them with exercise tolerance, in obese individuals with obstructive sleep apnea syndrome (OSAS). Methods: The sample comprised 31 adult subjects with moderate-to-severe OSAS diagnosed by polysomnography. We used spirometry to measure FVC, FEV ${ }_{1}$, and FVC/FEV ratio, using pressure manometry to measure MIP and MEP. The incremental shuttle walk test (ISWT) and the six-minute walk test (6MWT) were used in order to determine functional exercise capacity. Results: In this sample, the mean values for FVC (\% of predicted), FEV $(\%$ of predicted): MIP, and MEP were $76.4 \pm 12.3 \%, 80.1 \pm$ $6.3 \%, 60.0 \pm 21.9 \mathrm{cmH}_{2} \mathrm{O}$, and $81.3 \pm 22.2 \mathrm{cmH}_{2} \mathrm{O}$, respectively. The mean distances covered on the ISWT and 6MWT were $221 \pm 97 \mathrm{~m}$ and $480.8 \pm 67.3 \mathrm{~m}$, respectively. The ISWT distance showed moderate positive correlations with FVC $(r=0.658 ; p=$ $0.001)$ and $\mathrm{FEV}_{1}(r=0.522 ; p=0.003)$. Conclusions: In this sample of obese subjects with untreated OSAS, lung function, inspiratory muscle strength, and exercise tolerance were all below normal. In addition, we found that a decline in lung function, but not in respiratory muscle strength, was associated with exercise tolerance in these patients.
\end{abstract}

Keywords: Sleep apnea syndromes; Exercise tolerance; Respiratory function tests; Respiratory muscles.

\section{INTRODUCTION}

Obstructive sleep apnea syndrome (OSAS) is characterized by partial or total obstruction of the upper airways during sleep. ${ }^{(1-3)}$ Obstructive events are associated with oxyhemoglobin desaturation, sleep fragmentation or deprivation, hypoxemia, hypercapnia, dyspnea, as well as diurnal symptoms such as excessive daytime sleepiness. ${ }^{(3,4)}$ The etiology of OSAS is multifactorial, including craniofacial anatomical changes and obesity. Obese individuals present a higher risk of pharyngeal occlusion and altered respiratory mechanics. ${ }^{(5)}$

An increase in the volume of adipose tissue in the thoracic and abdominal regions impairs diaphragmatic function and reduces chest cavity compliance and lung volumes, leading to an increase in inspiratory muscle work. ${ }^{(6,7)}$ Episodes of recurrent hypoxia in OSAS are usually accompanied by microarousals to reestablish normal ventilation after occlusion of the upper airways. ${ }^{(8)}$ In addition, recurrent episodes of hypoxia and reoxygenation related to upper airway obstruction in OSAS are associated with abnormal partial pressure of oxygen and of carbon dioxide, reducing respiratory muscle activity and lung volumes. These factors generate new episodes of apneahypopnea throughout the night, limiting the ability to perform activities of daily living. ${ }^{(9-11)}$
Obesity and OSAS are factors that potentially alter aerobic capacity and exercise tolerance in different ways. The initial impairment of lung function and respiratory muscle function seen in obese individuals is related to reductions in functional exercise capacity and quality of life. ${ }^{(12,13)}$ There is also evidence that the lower-than-normal exercise tolerance in OSAS patients is due to OSAS-related episodes of dyspnea, intermittent hypoxemia, respiratory muscle dysfunction, and pulmonary hypertension. ${ }^{(14,15)}$ In obese patients with OSAS, cardiovascular diseases such as arterial hypertension, cardiac arrhythmia, and systolic dysfunction can also limit exercise tolerance, as can increased work of breathing, hypoventilation, and a sedentary lifestyle. ${ }^{(16,17)}$

The present study aimed to evaluate lung function and inspiratory muscle strength, correlating them with exercise tolerance, in obese individuals with OSAS.

\section{METHODS}

This was a cross-sectional, descriptive, observational study with quantitative analysis. We recruited individuals of either gender with a diagnosis of OSAS, confirmed through polysomnography, who were evaluated and treated at the Pulmonology Outpatient Clinic of the

Correspondence to:

Thays Maria da Conceição Silva Carvalho. Rua Dom Manoel de Medeiros. s/n, Dois Irmãos, CEP 52171-900, Recife, PE, Brasil.

Tel.: 5581 9899-0222. E-mail: annamyrna@uol.com.br

Financial support: This study received financial support from Coordenação de Aperfeiçoamento de Pessoal de Nive/ Superior (CAPES, Office for the

Advancement of Higher Education) 
Hospital Otávio de Freitas, located in the city of Recife (PE), Brazil. We applied the following inclusion criteria: having been diagnosed with moderate or severe OSAS; being between 50 and 70 years of age; being able to perform stress tests for functional capacity assessment; and having a body mass index (BMI) between $18 \mathrm{~kg} / \mathrm{m}^{2}$ and $40 \mathrm{~kg} / \mathrm{m}^{2}$. Patients with mild apnea-defined as a apnea-hypopnea index (AHI) between 5-15 events/h-were excluded, as were those with cardiopulmonary, neuromuscular, or orthopedic diseases that could influence or limit their ability to perform the tests, those with a BMI > $40 \mathrm{~kg} / \mathrm{m}^{2}$, and those being treated with continuous positive airway pressure. We initially evaluated 150 patients for eligibility, and 81 of those patients did not meet the inclusion criteria. Therefore, 69 patients were selected to perform the tests. However, 38 were excluded during the evaluation. Consequently, the final sample comprised 31 patients (Figure 1 ).

The sample size calculation was performed with MedCalc software, version 17.9.5 (MedCalc Software, Mariakerke, Belgium), considering as parameters a probabilistic error of 0.05 ( $5 \%$ alpha) and a statistical power of $80 \%$. Thus, the minimum number of subjects required was calculated to be 24 .

The research was approved by the human research ethics committee of the institution. All participants gave written informed consent.

All of the patients completed the Pittsburgh Sleep Quality Index questionnaire, which evaluates sleep quality in the last month. ${ }^{(18)}$ The Epworth Sleepiness Scale was used for the evaluation of excessive daytime sleepiness. ${ }^{(19)}$ The heart rate was measured with a heart monitor (model FT1; Polar, Kempele, Finland). Blood pressure was measured with an aneroid sphygmomanometer with an arm cuff (Premium model; Missouri Mikatos, Embu, Brazil) and a Rappaport premium stethoscope (Accumed, Rio de Janeiro, Brazil). The heart rate was measured at rest and immediately after the test. Systolic blood pressure (SBP) and diastolic blood pressure (DBP) were measured at rest, $1 \mathrm{~min}$ after the test, $3 \mathrm{~min}$ after the test, $5 \mathrm{~min}$ after the test, and $10 \mathrm{~min}$ after the test. The measurement of MIP and MEP followed the methodological recommendations of the American Thoracic Society/European Respiratory Society ${ }^{(20)}$ and the Brazilian Thoracic Association, ${ }^{(21)}$ with the use of a manometer (model MVD300; Globalmed, Porto Alegre, Brazil). We selected three (not necessarily sequential) tests that were considered acceptable (i.e., that met the reproducibility criteria). We used the measurement with the highest value, as long as it did not vary more than $10 \%$ in relation to the other values.

Through spirometry, also following the methodological recommendations of the Brazilian Thoracic Association, (21) the following variables were obtained: $\mathrm{FVC}_{1} \mathrm{FEV}_{1}$, and the $\mathrm{FEV}_{1} /$ FVC ratio.

We applied the incremental shuttle walk test (ISWT), in which the patient has to walk a $20-\mathrm{m}$ path $(10 \mathrm{~m}$ forward and $10 \mathrm{~m}$ back), according to the protocol

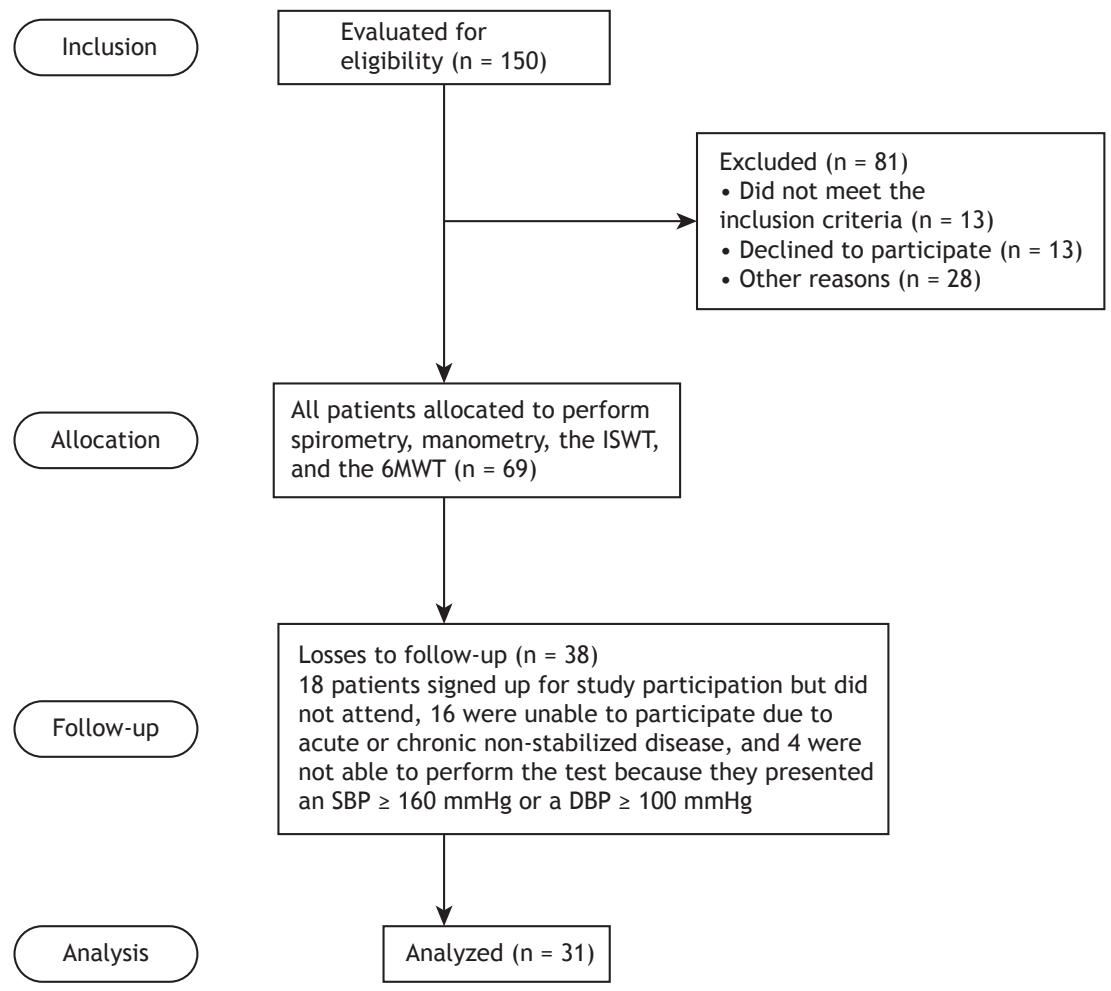

Figure 1. Flowchart of the study selection, allocation, follow-up, and analysis. ISWT: incremental shuttle walk test; 6MWT: six-minute walk test; SBP: systolic blood pressure; and DBP: diastolic blood pressure 
developed by Singh et al. (22) The path was delineated with two traffic cones. We also applied the six-minute walk test (6MWT), which was performed in accordance with the American Thoracic Society specifications. ${ }^{(23)}$

Descriptive analyses were presented as a mean \pm standard deviation or as median and interquartile range, as appropriate, according to the results of the Kolmogorov-Smirnov test. The correlations between variables were analyzed by Spearman's test, and the differences between the means were evaluated with the Student's t-test for independent samples. Values of $p<0.05$ were considered significant. The data were processed with the Statistical Package for the Social Sciences, version 16.0 (SPSS Inc., Chicago, IL, USA).

\section{RESULTS}

Table 1 presents demographic and polysomnographic characteristics of the population studied. We evaluated 31 patients, of whom $10(32.2 \%)$ were male and 21 $(67.8 \%)$ were female. The mean age was $58.8 \pm 5.4$ years, and the mean BMI was $31.2 \pm 5.0 \mathrm{~kg} / \mathrm{m}^{2}$. The mean AHI was $35.0 \pm 12.8$ events/h. Of the 31 patients evaluated, $14(45.2 \%)$ had moderate OSAS and 17 $(54.8 \%)$ had severe OSAS. Although all of the patients had poor sleep quality according to the Pittsburgh Sleep Quality Index, none showed excessive daytime sleepiness according to the Epworth Sleepiness Scale.

Table 2 presents data on lung function and respiratory muscle strength.

Table 3 presents comparisons of heart rates and blood pressure levels during the ISWT and the 6MWT. The following variables were significantly higher during the ISWT than during the 6MWT: SBP 1 min after the test ( $p=0.004)$, SBP 3 min after the test $(p=0.01)$, SBP 5 min after the test $(p=0.03)$, DBP 3 min after the test $(p=0.07)$, and DBP 5 min after the test ( $p=$

Table 1. Characteristics of the sample $(\mathrm{N}=31)$. $^{\text {a }}$

\begin{tabular}{|c|c|}
\hline Variables & Results \\
\hline Female & $21(67.7)$ \\
\hline Age, years & $58.8 \pm 5.4$ \\
\hline Weight, kg & $82.2 \pm 16.7$ \\
\hline Height, m & $1.63 \pm 0.06$ \\
\hline $\mathrm{BMI}, \mathrm{kg} / \mathrm{m}$ & $231.2 \pm 5.0$ \\
\hline Abdominal circumference, $\mathrm{cm}$ & $99.4 \pm 16.7$ \\
\hline Neck circumference, cm & $35.7 \pm 2.8$ \\
\hline AHI, events/h & $35.0 \pm 12.8$ \\
\hline $15-30$ events/h & $14(45.2)$ \\
\hline$>30$ events/h & $17(54,8)$ \\
\hline ESE & $9.19 \pm 4.4$ \\
\hline PSQI & $6.48 \pm 1.61$ \\
\hline \multicolumn{2}{|l|}{ Comorbidities $^{\mathrm{b}}$} \\
\hline Hypertension & $29(91.0)$ \\
\hline Diabetes & $22(61.5)$ \\
\hline
\end{tabular}

BMI: body mass index; AHI: apnea-hypopnea index; ESS: Epworth Sleepiness Scale; and PSQI: Pittsburgh

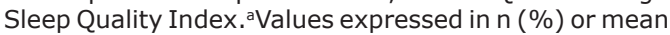
\pm SD. . Patients with these comorbidities were receiving antihypertensive or hypoglycemic medications.
0.001). The other variables did not present significant differences in the comparison between the two tests.

Table 4 shows Spearman's correlation coefficients for the anthropometric, spirometric, and inspiratory muscle strength variables related to the distances covered on the ISWT and the 6MWT. There was a strong, positive correlation between FVC and the distance covered on the ISWT ( $r=0.658, p=0.001)$, as well as a moderate positive correlation between the $\mathrm{FEV}_{1}$ and the distance covered on the ISWT ( $r=0.522 ; p=$ 0.003 ). However, we found no correlations in relation to any of the other parameters evaluated.

\section{DISCUSSION}

The main findings of the present study show that, in our obese patients with OSAS, lung function and inspiratory muscle strength were impaired. In addition, the functional exercise capacity was reduced and there was a significant positive correlation between the distance covered on the ISWT and the variables related to pulmonary function.

In the present study, the values obtained for spirometric parameters and respiratory muscle strength were lower than the reference values for the healthy Brazilian population. (24) In the study conducted by Tassinari et al., ${ }^{(25)}$ no impairment of lung function or the respiratory musculature was observed in patients with OSAS. However, the OSAS patients evaluated in that study were of normal weight, unlike those in our sample, all of whom were obese. Likewise, Gontijo et al., (26) studying obese individuals who did not present OSAS, obtained spirometric values within the limits of normality. The authors concluded that obesity would not be a factor associated with impairment of lung function. Studies indicate that obese individuals, due to the deposition of fat in the chest wall and abdomen, present a reduction in thoracic compliance, thus increasing the total work of breathing. $(3,27,28)$ The upper airway collapse and the apnea-hypopnea events resulting from OSAS have respiratory consequences, such as hypoxemia, alveolar hypoventilation, and hypercapnia. Hypoxia-reoxygenation events lead to the activation of peripheral chemoreceptors leading to increased ventilation to correct alterations in blood gases. ${ }^{(10)}$ Changes in $\mathrm{O}_{2}$ and $\mathrm{CO}_{2}$ concentrations result in a decrease in respiratory muscle activity and a reduction in lung volumes. ${ }^{(8,9)}$

Table 2. Data on pulmonary function and respiratory muscle strength. ${ }^{\mathrm{a}}$

\begin{tabular}{lc}
\multicolumn{1}{c}{ Variable } & Result \\
FVC, L & $2.4 \pm 0.6$ \\
FVC, \% predicted & $76.4 \pm 12.3$ \\
FEV $_{1}, \%$ predicted & $80.1 \pm 6.32$ \\
FEV $_{1}, \mathrm{~L}$ & $2.0 \pm 0.4$ \\
$\mathrm{FEV}_{1} / \mathrm{FVC}$ ratio & $79.6 \pm 5.8$ \\
$\mathrm{MIP}, \mathrm{cmH}_{2} \mathrm{O}$ & $60.0 \pm 21.9$ \\
$\mathrm{MEP}, \mathrm{cmH}_{2} \mathrm{O}$ & $81.3 \pm 22.2$ \\
\hline
\end{tabular}

avalues expressed as mean $\pm \mathrm{SD}$. 
Table 3. Variables collected during the incremental shuttle walk test and the six-minute walk test. ${ }^{a}$

\begin{tabular}{|c|c|c|c|c|}
\hline Variable & ISWT & 6MWT & $\Delta$ intergroup (95\% CI) & $p^{*}$ \\
\hline $\mathrm{HR}_{\text {rest, }}$ bpm & $72.9 \pm 7.9$ & $73.2 \pm 8.3$ & $-2.5(-4.3$ to 3.6$)$ & 0.901 \\
\hline $\mathrm{HR}_{\max ,}$, bpm & $121.9 \pm 14.7$ & $109.7 \pm 18.6$ & $12.1(3.6-20.7)$ & 0.006 \\
\hline $\mathrm{SBP}_{\text {rest }}, \mathrm{mmHg}$ & $117.1 \pm 5.8$ & $115.8 \pm 6.7$ & $1.2(-1.9$ to 4.4$)$ & 0.424 \\
\hline $\mathrm{SBP}_{\text {recovery 1, }}, \mathrm{mmHg}$ & $152.2 \pm 13.0$ & $138.3 \pm 10.0^{*}$ & $13.8(7.9-19.7)$ & 0.001 \\
\hline $\mathrm{SBP}_{\text {recovery 3, }}, \mathrm{mmHg}$ & $137.1 \pm 9.4$ & $128.0 \pm 7.9^{*}$ & $9.0(4.6-13.4)$ & 0.01 \\
\hline $\mathrm{SBP}_{\text {recovery 5, }}, \mathrm{mmHg}$ & $127.4 \pm 6.3$ & $119.3 \pm 6.9^{*}$ & $8.0(4.7-11.3)$ & 0.001 \\
\hline $\mathrm{SBP}_{\text {recovery } 10^{\prime}}, \mathrm{mmHg}$ & $119.3 \pm 4.4$ & $117.1 \pm 5.8$ & $2.2(-3.8$ to 4.9$)$ & 0.093 \\
\hline $\mathrm{DBP}_{\text {rest }}, \mathrm{mmHg}$ & $82.5 \pm 7.2$ & $82.2 \pm 7.1$ & $3.3(-3.3$ to 3.8$)$ & 0.861 \\
\hline $\mathrm{DBP}_{\text {recovery } 1}, \mathrm{mmHg}$ & $118.0 \pm 10.4$ & $108.0 \pm 11.3^{*}$ & $10.0(4.4-15.5)$ & 0.001 \\
\hline $\mathrm{DBP}_{\text {recovery 3, }}, \mathrm{mmHg}$ & $112.9 \pm 9.3$ & $103.5 \pm 13.5^{*}$ & $9.3(3.4-15.2)$ & 0.002 \\
\hline $\mathrm{DBP}_{\text {recovery 5}}, \mathrm{mmHg}$ & $101.9 \pm 12.2$ & $88.0 \pm 11.3^{*}$ & $13.8(7.8-19.8)$ & 0.001 \\
\hline $\mathrm{DBP}_{\text {recovery } 10}, \mathrm{mmHg}$ & $88.0 \pm 11.3$ & $82.9 \pm 7.8^{*}$ & $5.1(0.19-10.1)$ & 0.042 \\
\hline Walk distance, m & $221.0 \pm 97.0$ & $480.8 \pm 67.3$ & & \\
\hline
\end{tabular}

ISWT: incremental shuttle walk test; 6MWT: six-minute walk test; SBP: systolic blood pressure; and DBP: diastolic

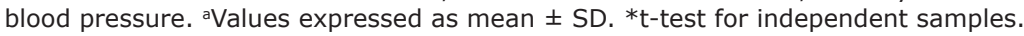

Table 4. Correlation between the selected variables and the distances covered on the incremental shuttle walk test and six-minute walk test.

\begin{tabular}{lcccc}
\multicolumn{1}{c}{ Variables } & ISWT & & \multicolumn{2}{c}{ 6MWT } \\
BMI & $\mathbf{r}$ & $\mathbf{p}$ & $\mathbf{r}$ & $\mathbf{p}$ \\
FEV $_{1}$ & -0.320 & 0.07 & -0.062 & 0.741 \\
FVC & 0.522 & 0.003 & 0.117 & 0.532 \\
MIP & 0.658 & 0.001 & 0.189 & 0.308 \\
Abdominal circumference & 0.075 & 0.069 & -0.105 & 0.575 \\
Neck circumference & 0.056 & 0.996 & -0.110 & 0.858 \\
AHI & -0.032 & 0.862 & -0.121 & 0.574 \\
\hline
\end{tabular}

ISWT: incremental shuttle walk test; 6MWT: six-minute walk test; BMI: body mass index; and AHI: index of apnea and hypopnea.

Regarding the association between pulmonary function and exercise tolerance, we found that FVC and FEV $_{1}$ showed significant positive correlations with the distance covered on the ISWT. This finding demonstrates that smaller lung volumes translate to lower exercise tolerance, underscoring the idea that pulmonary function affects exercise capacity in individuals with OSAS. Impairment of exercise capacity in obese individuals was also shown in another study, in which the authors concluded that being overweight is associated with a loss of self-esteem and lower psychic well-being. ${ }^{(29)}$ Factors such as dyspnea, abnormalities in respiratory mechanics, respiratory muscle dysfunction, and arterial hypoxemia contribute to limiting exercise tolerance in OSAS patients. ${ }^{(14)}$

In our study, the distance covered on both walk tests was lower than the reference distance for healthy individuals in the Brazilian population, ${ }^{(30-32)}$ indicating that exercise tolerance was below normal in our obese patients with OSAS. The patients in our sample also had comorbidities such as hypertension and type 2 diabetes mellitus. Exercise tolerance is directly related to the good performance of the cardiopulmonary system. Therefore, the impairment of functional exercise capacity in OSAS patients is multifactorial, being associated with obesity, a sedentary lifestyle, cardiovascular diseases, dyspnea, and respiratory abnormalities. ${ }^{(14,15)}$ However, there are conflicting data regarding the impaired exercise capacity resulting from the combination of OSAS with obesity in relation to exercise capacity. A study conducted by Beitler et al. ${ }^{(11)}$ showed that peak oxygen consumption $\left(\mathrm{VO}_{2 \text { peak }}\right)$ was significantly lower in obese OSAS patients than in controls, also reporting an association between $\mathrm{VO}_{2 \text { peak }}$ and the AHI. In contrast, Rizzi et al., ${ }^{(15)}$ in a study of normal-weight OSAS patients, observed no impairment of the functional exercise capacity. However, in a subsequent study-a randomized clinical trial involving obese and normal-weight individuals, with or without OSAS-Rizzi et al. (33) observed a significant difference in exercise tolerance between the obese and non-obese groups regardless of the presence ofOSAS, in terms of $\mathrm{CO}_{2}$ production and the maximum $\mathrm{VO}_{2}$. The authors concluded that obesity would be the main condition of low functional capacity, given that the obese patients presented low exercise tolerance, regardless of the presence or absence of OSAS.

Regarding the cardiovascular responses to the 6MWT in the present study, the cardiac parameters measured immediately after the test demonstrated marked 
increases in relation to the data collected during the test, results that are in agreement with those obtained by Rizzi et al. ${ }^{(33)}$ in their study of obese patients with OSAS. However, the cardiovascular responses were even more pronounced during and after the ISWT, as was also reported by Gonçalves et al. ${ }^{(34)}$ in a study of healthy individuals. In another study involving obese patients with OSAS, in which cardiopulmonary exercise testing (CPET) with the Bruce protocol was employed, ${ }^{(34)}$ patients with severe apnea were found to show an increase in blood pressure during peak exercise with a return to basal blood pressure levels after exercise. Green et al. ${ }^{(35)}$ stated that the ISWT provokes a physiological response to exercise similar to that observed during CPET.

Although the 6MWT is a standard test in the clinical assessment of effort in patients with OSAS $^{(25)}$ and obese patients, ${ }^{(36)}$ the ISWT has also proven to be feasible and reliable in the assessment of effort tolerance in individuals with OSAS. Green et al. ${ }^{\left({ }^{35)}\right.}$ studied patients with heart failure, comparing the responses obtained with CPET, the ISWT, and the 6MWT. They concluded that the ISWT provided a valid index to determine functional capacity in individuals with heart failure and that the predictive power of the ISWT could exceed that of the 6MWT. In a study evaluating patients with moderate or severe OSAS, Billings et al.(37) used the ISWT to compare physical fitness before and after treatment with continuous positive airway pressure. The authors concluded that the ISWT is safe, well tolerated, and easily reproducible in OSAS patients, supporting the idea that it can be used safely in the evaluation of exercise tolerance in such patients.

Our study has limitations, such as the small sample size. However, the number of patients evaluated was within the limits set in the sample calculation. In addition, we did not perform CPET, which is the gold standard test in the analysis of functional capacity and of cardiopulmonary impairment and would have allowed a more reliable evaluation of the cardiovascular parameters, as well as their subsequent correlation with those found on the two other tests. Another limitation was the fact that our study evaluated only obese patients with OSAS and there was no control group of obese patients without OSAS. Furthermore, data regarding cardiovascular comorbidities were not available for the patients in the sample studied. Therefore, studies with greater methodological rigor, such as randomized clinical trials, are needed in order to increase knowledge about the subject in the future.

The results found in the present study show that obese subjects with untreated OSAS presented below-normal lung function, inspiratory muscle strength, and physical capacity. In addition, it was observed that the decline in lung function, but not inspiratory muscle strength, is associated with physical effort tolerance in these patients, which makes it necessary to use therapeutic interventions to improve variables such as physical exercise. We can also emphasize that the ISWT was able to evaluate the exercise tolerance in OSAS, making it quite useful in the clinical investigation of the disease, due to its low cost, reproducibility, and ease of application.

\section{REFERENCES}

1. Huang JF, Chen LD, Lin OC, Chen GP, Yu YH, Huang JC et al. The relationship between excessive daytime sleepiness and metabolic syndrome in severe obstructive sleep apnea. Clin Respir J 2016;10(6):714-721. https://doi.org/10.1111/crj.12276

2. Hsia JC. Anatomy and physiology of the upper airway in obstructive sleep apnea. Oper Tech Otolayngol Head Neck Surg. 2015;26(2):7477. https://doi.org/10.1016/j.otot.2015.03.005

3. Wimms A, Woehrle $H$, Ketheeswaran S, Ramanan D, Armitstead J. Obstructive sleep apnea in women: specific issues and interventions. Biomed Res Intern. 2016;2016:1764837. https://doi. org/10.1155/2016/1764837

4. Cholidou KG, Manali ED, Kapsimalis F, Kostakis ID, Vougas K Simoes $D$, et al. Heart rate recovery post 6 minute walking test in obstrtuctive sleep apnea: cycle ergometry versus 6-minute walking test in OSA patients. Clin Res Cardiol. 2014;103(10):805-15. https:// doi.org/10.1007/s00392-014-0721-3

5. Martins $A B$, Tufik $S$, Moura SM. Physiopathology of obstructive sleep apnea-hypopnea syndrome. J Bras Pneumol. 2007;33(1):93100. https://doi.org/10.1590/S1806-37132007000100017

6. Salome CM, King GG, Berend N. Physiology of obesity and effects on lung function. J Appl Physiol (1985). 2010;108(1):206-11. https:// doi.org/10.1152/japplphysiol.00694.2009

7. Melo LC, Silva MA, Calles AC. Obesity and lung function: a systematic review. Einstein (Sao Paulo). 2014;12(1):120-5. https:// doi.org/10.1590/S1679-45082014RW2691

8. Haggstram FM, Zettler EW, Fam CF. Apnéia obstrutiva do sono e alterações cardiovasculares. Scientia Med (Porto Alegre). 2009;19:122-8.

9. Yokhana SS, Gerst DG 3rd, Lee DS, Badr MS, Qureshi T, Mateika $\mathrm{JH}$. Impact of repeated daily exposure to intermittent hypoxia and mild sustained hypercapnia on apnea severity. J Appl Physiol (1985). 2012;112(3):367-77. https://doi.org/10.1152/japplphysiol.00702.2011
10. Mateika JH, Syed Z. Intermittent hypoxia, respiratory plasticity and sleep apnea in humans: present knowledge and future investigations. Respir Physiol Neurobiol. 2013;188(3):289-300. https://doi.org/10.1016/j.resp.2013.04.010

11. Beitler JR, Awad KM, Bakker JP, Edwards BA, DeYoung P, Djonlagic I, et al. Obstructive sleep apnea is associated with impaired exercise capacity: a cross-sectional study. J Clin Sleep Med. 2014;10(11):1199 204. https://doi.org/10.5664/jcsm.4200

12. Çiçek D, Lakadamyali H, Gökay S, Sapmaz I, Muderrisoglu H Effect of obstructive sleep apnea on heart rate, heart rate recovery and QTC and P-wave dispersion in newly diagnosed untreated patients. Am J Med Sci. 2012;344(3):180-5. https://doi.org/10.1097/ MAJ.0b013e318239a67f

13. Rasslan Z, Saad R Jr, Stirbulov R, Fabbri RM, Lima CA Evaluation of pulmonary function in class I and II obesity. J Bras Pneumol. 2004;30(6):508-14. https://doi.org/10.1590/S180637132004000600004

14. Lin CC, Hsieh WY, Chou CS, Liaw SF. Cardiopulmonary exercise testing in obstructive sleep apnea syndrome. Respir Physiol Neurobiol. 2006;150(1):27-34. https://doi.org/10.1016/j. resp.2005.01.008

15. Rizzi CF, Cintra F, Risso T, Pulz C, Tufik S, de Paola A, et al. Exercise capacity and obstructive sleep apnea in lean subjects. Chest. 2010;137(1):109-14. https://doi.org/10.1378/chest.09-1201

16. Ryan S. Adipose tissue inflammation by intermittent hypoxia: mechanistic link between obstructive sleep apnea and metabolic dysfunction. J Physiol. 2017;595(8):2423-2430. https://doi. org/10.1113/JP273312

17. Brum PC, Forjaz CL, Tinucci T, Negrão CE. Adaptações agudas e crônicas do exercício físico no sistema cardiovascular. Rev Paul Educ Fis. 2004;18:21-31

18. Bertolazi AN, Fagondes SC, Hoff LS, Dartora EG, Miozzo IC, de 
Barba ME, et al. Validation of the Brazilian Portuguese version of the Pittsburgh Sleep Quality index. Sleep Med. 2011;12(1):70-5. https:/ doi.org/10.1016/j.sleep.2010.04.020

19. Bertolazi AN, Fagondes SC, Hoff LS, Pedro VD, Menna Barreto SS, Johns MW. Portuguese-language version of the Epworth sleepiness scale: validation for use in Brazil. J Bras Pneumol. 2009;35(9):877-83. https://doi.org/10.1590/S1806-37132009000900009

20. American Thoracic Society/European Respiratory Society. ATS/ERS Statement on respiratory muscle testing. Am J Respir Crit Care Med. 2002;166(4):518-624. https://doi.org/10.1164/rccm.166.4.518

21. Sociedade Brasileira de Pneumologia e Tisiologia. Diretrizes para testes de função pulmonar. J Pneumol. 2002;28(Suppl 3):S1-S238.

22. Singh SJ, Morgan MD, Scott S, Walters D, Hardman AE. Development of a shuttle walking test of disability in patients with chronic airways obstruction. Thorax. 1992;47(12):1019-24. https:/ doi.org/10.1136/thx.47.12.1019

23. ATS Committee on Proficiency Standards for Clinical Pulmonary Function Laboratories. ATS statement: guidelines for the six-minute walk test. Am J Respir Crit Care Med. 2002;166(1):111-7. https://doi. org/10.1164/ajrccm.166.1.at1102

24. Pereira CA, Sato T, Rodrigues SC. New reference values for forced spirometry in white adults in Brazil. J Bras Pneumol. 2007;33(4):397406. https://doi.org/10.1590/S1806-37132007000400008

25. Tassinari CC, Piccin CF, Beck MC, Scapini F, Oliveira LC, Signori LU, et al. Capacidade funcional e qualidade de vida entre sujeitos saudáveis e pacientes com apneia obstrutiva do sono. Medicina (Rib Preto). 2016;49(2):152-9. https://doi.org/10.11606/issn.2176-7262. v49i2p152-159

26. Gontijo PL, Lima TP, Costa TR, Reis EP, Cardoso FP, Cavalcant Neto FF. Correlation of spirometry with the six-minute walk test in eutrophic and obese individuals. Rev Assoc Med Bras (1992). 2011;57(4):380-6. https://doi.org/10.1016/S0104-4230(11)70081-1

27. Zieliński J. Effects of intermittent hypoxia on pulmonary haemodynamics: animal models versus studies in humans. Eur Respir J. 2005;25(1):173-80. https://doi.org/10.1183/09031936.04.0 0037204
28. Cordeiro AL, de Melo TA, Neves D, Luna J, Esquivel MS, Guimarães $A R$, et al. Inspiratory Muscle Training and Functional Capacity in Patients Undergoing Cardiac Surgery. Braz J Cardiovasc Surg 2016;31(2):140-4

29. Tavares TB, Nunes SM, Santos MO. Obesidade e qualidade de vida: revisão de literatura. Rev Med Minas Gerais. 2010;20:359-66.

30. Soares KK, Gomes EL, Junior AB, Oliveira LV, Sampaio LM, Costa D. Avaliação do desempenho físico e funcional respiratório em obesos. Fisioter Mov. 2011:24(4):697-704. https://doi.org/10.1590/S010351502011000400014

31. Fernandes PM, Pereira NH, Santos AC, Soares ME. Teste de caminhada de seis minutos: avaliação da capacidade funcional de indivíduos sedentários. Rev Bras Cardiol. 2012;25(3):185-91.

32. Dourado VZ, Guerra RL, Tanni SE, Antunes LC, Godoy I. Reference values for the incremental shuttle walk test in healthy subjects: from the walk distance to physiological responses. Bras Pneumol. 2013;39(2):190-7. https://doi.org/10.1590/S180637132013000200010

33. Rizzi CF, Cintra F, Mello-Fujita L, Rios LF, Mendonca ET, Feres $\mathrm{MC}$, et al. Does obstructive sleep apnea impair the cardiopulmonar response to exercise? Sleep. 2013;36(4):547-53. https://doi. org/10.5665/sleep. 2542

34. Gonçalves CG, Hayashu D, Mesquita R, Pitta F, Fernandes KB Probst VS. Teste de campo "incremental shuttlle walking test" impõe esforço máximo a indivíduos saudáveis de diferentes faixas etárias? Rev Bras Fisioter. 2012;16:364-74

35. Green DJ, Watts K, Rankin S, Wong P, O'Driscoll JG. A Comparison of the shuttle and 6 walking tests with measured peak oxygen consumption in patients with heart failure. J Sci Med Sport. 2001;4(3):292-300. https://doi.org/10.1016/\$1440-2440(01)80038-4

36. Perecin JC, Domingos-Benício NC, Gastaldi AC, Sousa TC, Cravo SL, Sologuren MJ. Teste de caminhada de seis minutos em adultos eutróficos e obesos. Rev Bras Fisioter. 2003;7(3):245-51.

37. Billings $C G$, Aung $T$, Renshaw SA, Bianchi SM. Incremental shuttle walk test in the assessment of patients with obstructive sleep apnea-hypopnea syndrome. J Sleep Res. 2013;22(4):471-7. https:// doi.org/10.1111/jsr.12037 